\title{
Lexical Aspect and L1 Transfer in the Acquisition of Tense-Aspect
}

\section{Morphology}

Cuijing Qian

School of Foreign Languages, Inner Mongolia University for the Nationalities, Tongliao, 028000, China

\begin{abstract}
This study aims to investigate the acquisition of English verb morphology by learners of two typologically different L1s and the role of L1 transfer in the acquisition pattern, a cross-sectional study ( $\mathrm{n}=$ 180) carried with Chinese and Mongolian college students learning English at two proficiency levels, using the cloze passage and composition. 120 cloze passages and 20 compositions were selected as data to be analyzed. Consistent with the Aspect Hypothesis, the results of MANOVA tests show a significant effect of lexical aspect on tense-aspect marking use: the perfective and past markings are strongly associated with Achievements/Accomplishments; the progressive marking is strongly associated with Activities; the present marking is strongly associated with States. Even though Mongolian and Chinese learners show virtually the same acquisition pattern, their performances in using the past, perfective, and progressive markings are different. Mongolian learners exhibiting superiority over Chinese learners in associating and correctly using the perfective and progressive markings, overuse of progressive markings by Mongolian learners, and overextending progressive markings to States by both L1 groups evidence L1 transfer. Contradictory findings-greater use and correct use of past markings with States than with Activities, overextending progressive markings to States, and learners' preference for using progressive markings with Achievements to Accomplishments suggest that the methodology, L1, sentence structures and input may somewhat affect the results of tense-aspect marking studies.
\end{abstract}

Key words: the Aspect Hypothesis, Lexical aspect, Tense-aspect morphology

\section{Introduction}

The acquisition of tense and aspect in second language (L2) has been a prolific topic of research in the field of the language acquisition since the 1980's. In most languages, a finite verb in each sentence has to be linguistically encoded for tense or aspect, or both. The studies aiming to uncover the nature of grammatical acquisition are of great importance to the development of the second language acquisition theory, which will consequently guide the practical language teaching and learning.

A large body of studies has explored the relationship between verb semantics and the development of tense-aspect morphology. Some researchers have claimed that the developmental sequence of tense-aspect morphology in first language (L1) and L2 acquisition follows a universal pattern and is strongly influenced by the inherent semantic aspect of the verbs to which the inflections are to attach (e.g., Shirai \& Andersen, 1995; Weist, 2002 in L1; Robison, 1995; Bardovi-Harlig \& Reynolds, 1995; Andersen, 1991 in L2). This tendency has been referred to as the Aspect Hypothesis first proposed by Roger Andersen (1991) based on the pioneering work of Vender, Weist and others. This hypothesis obtains the bulk of supporting evidence from the studies on L2 acquisition of both Indo-European languages (e.g., English, Spanish, Italian, and French) and non-Indo-European languages (e.g., Japanese, Chinese) with subjects from different language backgrounds by using different methodologies

Some recent studies, however, have uncovered some discrepancies with the proposed tenets of the Aspect Hypothesis. Accounting for the counter-evidence, Salaberry \& Shirai (2002) point out that the simple form-meaning correlation is only one part of the picture which is conditioned by various factors: L1 transfer, 
input data and its processing, formation of prototypes, discourse functions, instructional variables, cognitive or universal constraints. Their viewpoints are in line with those of Andersen (2002), Rohde (2002), Duff \& Li (2002) and Bardovi-Harlig (2000). Therefore, the research into the possible effect of that particular features and of the native language on the processing and development of the target language would be conducive to the interpretation of the development of interlanguage grammar.

\section{The Aspect Hypothesis}

The Aspect Hypothesis is based on the theory of lexical aspect. Lexical aspect, also known as situation type (Smith, 1983), refers to the inherent characteristics of the lexical items that describe a situation or action. According to Smith (1991), lexical aspect is expressed lexically by the inherent lexical semantics of the verb and its interaction with direct and indirect arguments and adjuncts, in terms of dynamicity, telicity, and punctuality. Dynamicity distinguishes dynamic events from states. States have no beginning and end point and do not require energy to ensure its existence while dynamic situations involve process and require energy to sustain its occurrence. Telicity refers to whether an event has an inherent end point. Punctuality distinguishes durative events that involve a span of time from punctual events that are instantaneous.

Based on these properties, Vendler's (1967) four-way classification of verbal predicates into four semantic types can be interpreted in the following ways, though Vendler did not explicitly discuss these notions.

States are static, durative (e.g., know, want, love etc.);

Activities are dynamic, durative, atelic (e.g., walk in the garden, cry etc.);

Accomplishments are dynamic, durative, telic (e.g., draw a picture, build a house etc.);

Achievements are dynamic, instantaneous, telic (e.g., break the glasses, recognize someone etc.).

States are nondynamic, in contrast to the other three categories which are dynamic, and persist over time without change. Within the dynamic set, Activities are atelic and nonpunctual, having an arbitrary end point and inherent duration. Accomplishments and Achievements are both telic, having a natural end point. For this reason, Andersen (2002) subsumes them under one category-event: Accomplishments require a period of an activity-like duration before reaching an endpoint and are also called telic events; Achievements are instantaneous in that the beginning and the end point are reduced to a point and are also called punctual events.

Plenty of research studies on L1 and L2 acquisition of tense-aspect morphology show a close correlation between the use of tense-aspect marking and inherent lexical aspect of the verb. It has been found that both L1 and L2 learners follow the same acquisition pattern, which refers to the Aspect Hypothesis: learners first associate the perfective past marking with lexical aspect in the order of Achievements/ Accomplishments $\rightarrow$ Activities $\rightarrow$ States and the progressive marking with lexical aspect in the order of Activities $\rightarrow$ Accomplishments $\rightarrow$ Achievements. The progressive marking does not incorrectly overextend to States. Such prototypical association is stronger at the early stages, and then gradually weakened over time. That is to say, lower-level learners are more constrained by inherent lexical aspect.

\section{Previous Research on the Aspect Hypothesis}

A large body of studies in L2 acquisition has accumulated evidence that inherent lexical aspectual classes constrain the acquisition of verbal morphology in both naturalistic and classroom settings in SLA including English, Spanish, French, Italian, Japanese and Chinese. The subjects involve children and adult L2 learners from a variety of first language backgrounds. The elicitation methods vary from oral or written narratives, cloze passages and judgment tasks. 
Since most learners in China are English learners, studies in the acquisition of English as L2 are mainly reviewed. These studies have specifically reported quantitative data relative to the perfective past and progressive markings in connection with lexical aspect.

\subsection{Supporting Evidence for the Aspect Hypothesis}

The spread of perfective past: it is by far the most widely explored in the distribution of tense-aspect morphology in both L1 and L2 acquisition, not only because the perfective past occur more frequently, but also it is the first past morpheme acquired and thus easily observed. Ample evidence supporting for this stage is found in English in both cross-sectional studies (Robinson, 1995; Bardovi-Harlig \& BergstrÖm, 1996; Bardovi-Harlig \& Reynolds, 1995; Bardovi-Harlig, 1998; Collins, 2002 ) and longitudinal studies (Robison, 1990; Rocca, 2002; Lee, 2001). Though those findings are unanimously claimed to be compatible with the predictions of the hypothesis, they subtly differ in the expansion paths of tense-aspect morphology across four verb categories. Some studies (Bardovi-Harlig and Reynolds, 1995; Collins, 2002; Rocca, 2002) find no difference between Achievements/Accomplishments in the rate of past marking use, while other studies (Robison, 1990, 1995; Bardovi-Harlig \& BergstrÖm, 1996; Bardovi-Harlig, 1998) differentiate between Achievements /Accomplishments.

The spread of progressive: the progressive has been widely investigated in English though less wildly investigated than the perfective past. Since Robison's (1995) study demonstrates that -ing correlates strongly with Activities in acquiring English, the same tendency has been discerned in other cross-sectional studies (Bardovi-Harlig \& Reynolds, 1995 and Collins, 2002 in written cloze passages; Bardovi-Harlig \& BergstrÖm, 1996 in written narratives; Bardovi-Harlig, 1998 in written and oral narratives). Similarly, in longitudinal studies (Housen, 2002, based on the data from conversation, personal narratives, picture description and story-telling; Rocca, 2002, based on the data from spontaneous production, retell task and cloze; Lee, 2001, based on the data from spontaneous conversation, story narrative, story translation, and picture description), the results reinforce the earlier findings regarding the strong correlation between the progressive marking and Activities.

The spread of simple present: the putative correlation of the simple present marking $-s$ or zero morpheme is often neglected from surveys of the Aspect Hypothesis. Only Robison (1995), Rohde (1996) and Housen (2002) explicitly examine the link between inherent aspect and the development of the simple present marking. In the first two studies, the interdependence of $-s$ or zero morpheme with States is significant, which is also observed in the studies of Bardovi-Harlig \& Reynolds (1995), Bardovi-Harlig \& BergstrÖm (1996) and Collins (2002). However, in Housen's study, the distribution of $-s$ does not show the link with States.

In sum, the Aspect Hypothesis is widely supported in one way or the other. Some studies, however, obtain findings that have been regarded by those researchers as counterevidence against the Aspect Hypothesis, which requires careful consideration.

\subsection{Counterevidence against the Aspect Hypothesis}

Four instances of potential counterevidence are reviewed here. The first and most frequently reported counterexample is non-target-like overextension of the progressive marker -ing to States. Robison (1990) reports a high rate of use of the progressive with States by the untutored learner of English (22\%). In Rohde's (1996) study with two untutored children learners, there are four tokens using -ing with States. As Bardovi-Harlig (2002) observed, tutored learners show no greater than 3\% use of the progressive with States in oral and written narratives tasks (Bardovi-Harlig, 1998; Bardovi-Harlig \& BergstrÖm, 1996; Robison, 1995; Lee, 2001), whereas, in cloze passage tasks, such correlation is up to 7\% in Bardovi-Harlig \& Reynolds's 
(1995) study and 9\% in Collins's (1997, as cited in Bardovi-Harlig, 2002) study. Therefore, she makes a tentative conclusion that most adult L2 language learners rarely overextend the use of the progressive to States and task may influence the rate of use. However, Housen's (2002) analysis of the data from conversation and oral narratives of tutored learner-Ema exhibits as great as $32 \%$ and $22 \%$ use of the progressive with States in the third and fourth interviews. The same high rate of progressive states use is also obtained in Rocca's (2002) longitudinal study based on the data from spontaneous production, retell task and cloze with tutored Italian learners. Such results disconfirm Bardovi-Harlig's conclusion. Housen and Rocca attribute learners' producing overextended stative progressives to the influence of input and L1 respectively.

A second and related counterexample is the highest association of the progressive marking -ing with Achievements rather than Activities reported by Rohde (1996) and Robison (1995). Since the progressive achievements occur particularly in future contexts in Rohde longitudinal studies with German children, He attributes the use of the progressive with Achievements to the use of -ing for future reference. In English, future uses are allowed with volitional Achievements such as he is leaving. The learner's tendency to interpreting -ing as the marker of future tense rather than as the redundant marker of inherent aspect or grammatical aspect demonstrate that neither inherent aspect nor grammatical aspect are universally primary in SLA. However, Robison states that the notable affiliation of progressive markings with Achievements is due to the form going to which appears more frequently in the input and "the elevated application of -ing to punctual events thus appears to be artificially induced” (p. 357). Since the affiliation of progressive markings with Achievements decreases with proficiency level while the association of progressive markings with Activities increases, Robison does not interpret such affiliation as a genuine counterexample.

Still, Rohde (1996, 2002) presents a third problematic result regarding the perfective past. Rohde (1996) examines the distribution of inflected and uninflected verb forms in past contexts. Though the use of the past marking is strongly associated with Achievements, the association is particularly apparent for the regular past (-ed) while the irregular past does not show this trend. His later study in 2002 reveals that a few Achievements remain uninflected and States have a very high past marking rate in obligatory past contexts. He thus suggests that learners' external factors (e.g., input) and internal factors (e.g., L1 transfer) may determine the degree to which the predictions of the Aspect Hypothesis are met. Housen (2002) also finds that learners mark States for past tense in the earlier stages of morphological development than expected and these States are mostly irregular verbs. Housen argues that the processing mechanism for the regular past is different from that of the irregular past which is more prone to rote learning than the regular past. In addition, in cross-sectional studies, all groups but group 1 in Bardovi-Harlig \& BergstrÖm's (1996) study as well as learners at level 4 and 5 in Bardovi-Harlig \& Reynolds's (1995) study show a higher past marking use on States than on Activities. Collins's (2002) replication studies reveal that States consistently have a higher rate of past marking than Activities at all six levels.

The last potential counterexample is that less advanced learners are not necessarily more restricted to the prototypes (Achievements for past marking and Activities for progressive marking) than more advanced learners (Robison, 1995; Bardovi-Harlig \& BergstrÖm, 1996; Bardovi-Harlig, 1998). Their studies all demonstrate that the prototypical association is not the strongest at the lower levels of proficiency but it is the strongest at higher levels, which apparently goes against the prediction of the Aspect Hypothesis. However, Bardovi-Harlig \& Reynolds (1995) and Collins (2002) find the predicted accuracy order of Accomplishments/Achievements $\rightarrow$ Activities $\rightarrow$ States for each proficiency group, and the accuracy rate increases as the proficiency level increases.

\section{L1 Transfer in the Acquisition of Tense-Aspect Morphology}


In viewing aforementioned research findings, it can be concluded that the Aspect Hypothesis is associated with four predictions concerning form-meaning association, but it is only a partial picture of interlanguage. Other factors, such as discourse, instruction, L1 transfer and input that may affect the acquisition sequence of interlanguage need to be explored. The role of discourse and instruction has been attested in Bardovi-Harlig' studies (2000, 2001), but she seems to hold a negative attitude to the role of L1 influence since she finds no significant L1 effect by reviewing the studies with mixed first language backgrounds' learners (Giacalone Ramat, 1992, 1995; Bardovi-Harlig \& Reynolds, 1995). However, in recent studies some researchers interpret the deviation from the pattern predicted by the Aspect Hypothesis as the influence of L1.

Investigating the data from Dutch and French learners of English, Housen (2002) finds that learners are more apt to use -ed and the irregular past form as markers of past tense than to use -ing as a marker of progressive aspect. Housen interprets it as the L1 transfer given that Dutch and French are tense-prominent languages while English is more aspect-prominent. He considers it as conceptual transfer that "a speaker's mind is set to a particular mode of thinking for speaking in the course of L1 acquisition and it is very difficult to reset it in the course of L2 acquisition”(p. 189).

In the acquisition of other languages like Italian, Chinese, Japanese, L1 influence has been confirmed. The conceptual transfer is also claimed by Giacalone-Ramat (2002). German learners of Italian overuse passato prossimo to code the imperfective past because in German grammar there is no morphologically marked aspectual distinctions, so learners have difficulty in choosing between imperfective and passato prossimo and late or seldom use the progressive aspect.

Duff \& Li (2002) examine the acquisition of the perfective aspect marker -le in Mandarin Chinese by native English speakers and native speakers of Chinese. Their results show that L2 learners with low proficiency levels tend to undersupply -le in oral narratives and oversupply it with certain stative and non-perfective activity verbs in the editing task. They argue that in the early L2 acquisition and production of $-l e$, learners adopt - $l e$ as the equivalent of the English past tense morpheme - ed, so they use it to describe past situations in Mandarin, irrespective of whether "the verb representing the event is stative or active inherently bounded. Such transfer is understandable, considering the overlap between past and perfertive events” (p. 445).

Shirai (2002) reviews the studies testing the acquisition pattern of Japanese tense-aspect morphology. Among these studies, Sheu (1997), Koyama (1998), and Shibata (1999) (as cited in Shirai, 2002) all suggest that there is an effect of L1 transfer in the acquisition of the progressive marking -te $i$ - by Chinese, Korean, and English learners, which can convey the progressive meaning when combined with Activities and the resultative meaning when combined with Achievements. In particular, Sheu's study shows "a strong influence of L1 in Chinese learners' production of -te $i$ - when referring to resultative state: the learner has much more difficulty in producing the correct form when the L1 equivalent is not expressed by the imperfective marker -zhe" (Shirai, 2002, p. 8).

Though the possibility of L1 influence is regarded as a contributing factor to the acquisition of tense and aspect morphology, there have been rare published studies systematically designed to test the effect of L1, except Collins (2002) and Cai's (2001) studies. Collins's replication studies of Bardovi-Harlig \& Reynolds (1995) with Francophone learners of English show that the perfect (similar in form but not function to the French passé composé) is the most common alternative to simple past for telics, which is the evidence of L1 influence on the acquisition pattern of tense and aspect morphology. Cai finds that Chinese aspect markers (-zhe, -le, -guo) have positive effects on the use of tense and aspect morphology in English through analyzing data collected through a Chinese-English translation test.

In viewing of those studies mentioned or designed to test the effect of L1 transfer, they either have too few subjects investigated or too few different verbs examined (Housen, 2002; Giacalone-Ramat, 2002; Shibata, 
1999, as cited in Shirai, 2002). Therefore more cross-sectional tests with data from other L1 groups, especially typologically different L1s groups are needed.

\section{Conclusion}

Though the bulk of evidence supports the distribution pattern and development sequences predicted by the Aspect Hypothesis, the reported counterexamples cannot so easily be discarded. More empirical studies are required to investigate whether the prediction of the Aspect Hypothesis is universal or need modifications by incorporating the role of other factors (e.g., input, L1 transfer), especially studies with learners whose L1 is typically different from the target language (e.g. Chinese) and learners who have never been tested to date (e.g. Mongolian).

\section{Acknowledgments}

Thanks for the support of the Inner Mongolia philosophy and social science planning project in 2013(No.2013B132).

\section{References}

Andersen, R. W. (1991). Developmental sequence: The emergence of aspect marking in second language acquisition. In T. Huebner \& C. A. Ferguson (Eds.), Crosscurrents in second language acquisition and linguistic theories (pp. 305-324). Amsterdam: Benjamins.

Andersen, R. W. (2002). The dimensions of "Pastness”. In R. Salaberry \& Y. Shirai (Eds.), The L2 acquisition of tense-aspect morphology (pp.79-105). Amsterdam: Benjamins.

Bardovi-Harlig, K. (1998). Narrative structure and lexical aspect: Conspiring factors in second language acquisition of tense-aspect morphology. Studies in Second Language Acquisition, 20, 471-508.

Bardovi-Harlig, K. (2000). Tense and aspect in second language acquisition: Form, meaning and use. Language Learning, 50, Supplement 1.

Bardovi-Harlig, K. (2001). Another piece of the puzzle: The emergence of the present perfect. Language Learning, 51, Suppl., 215-264.

Bardovi-Harlig, K. (2002). Analyzing aspect. In R. Salaberry \& Y. Shirai (Eds.), The L2 acquisition of tense-aspect morphology (pp.129-154). Amsterdam: Benjamins.

Bardovi-Harlig, K., \& BergstrÖm, A. (1996). Acquisition of tense and aspect in second language and foreign language learning: Learner narratives in ESL and FFL. The Canadian Modern Language Review, 52, 308-330.

Bardovi-Harlig, K., \& Reynolds, D. W. (1995). The role of lexical aspect in the acquisition of tense and aspect. TESOL Quarterly, 29, 107-131.

Cai, J. T. (2001, July). The influence of Chinese aspect markers on the use of tense and aspect in English as a foreign language. Paper presented at the $2^{\text {nd }}$ International Conference on English Teaching in Asia, Nanjing.

Collins, L. (2002). The roles of L1 influence and lexical aspect in the acquisition of temporal morphology. Language Learning, 52, 43-94.

Duff, P. A., \& Li, D. (2002). The acquisition and use of perfective aspect in Mandarin. In R. Salaberry \& Y. Shirai (Eds.), The L2 acquisition of tense-aspect morphology (pp. 417-453). Amsterdam: Benjamins.

Giacalone-Ramat, A. (1992). Grammaticalization process in the area of temporal and modal relations. Studies in Second Language Acquisition, 14, 297-332.

Giacalone-Ramat, A. (1995). Iconicity in grammaticalization processes. In R. Simon (Eds.), Iconicity in language (pp. 191-139). Amsterdam: Benjamins. 
Giacalone-Ramat, A. (2002). How do learners acquire the classical three categories of temporality: Evidence from L2 Italian. In R. Salaberry \& Y. Shirai (Eds.), The L2 acquisition of tense-aspect morphology (pp. 221-247). Amsterdam: Benjamins.

Housen, A. (2002). The development of tense-aspect in English as a second language and the variable influence of inherent aspect. In R. Salaberry \& Y. Shirai (Eds.), The L2 acquisition of tense-aspect morphology (pp. 155-197). Amsterdam: Benjamins.

Koyama, S. (1998, December). The acquisition of tense-aspect by learners of Japanese[Nihongo gakusyuusya ni yoru tensu asupekuto no syuutoku]. Paper presented at the $9^{\text {th }}$ National Meeting of the Japanese Association of Second Language Acquisition, Nagoya University.

Lee, E. J. (2001). Interlanguage development by two Korean speakers of English with a focus on temporality. Language Learning, 51, 591-633.

Robison, R. (1990). The primacy of aspect: Aspectual marking in English interlanguage. Studies in Second Language Acquisition, 12, 315-330.

Robison, R. (1995). The aspect hypothesis revisited: A cross-sectional study of tense and aspect marking in interlanguage. Applied Linguistics, 16, 344-370.

Rocca, S. (2002). Lexical aspect in child second language acquisition of temporal morphology: A bi-directional study. In R. Salaberry \& Y. Shirai (Eds.), The L2 acquisition of tense-aspect morphology (pp. 249-284). Amsterdam: Benjamins.

Rohde, A. (1996). The aspect hypothesis and emergence of tense distinction in naturalistic L2 acquisition. Linguistics, 34, 1115-1138.

Rohde, A. (2002). The aspect hypothesis in naturalistic L2 acquisition: What uninflected and non-target-like verb forms in early interlanguage tell us. In R. Salaberry \& Y. Shirai (Eds.), The L2 acquisition of tense-aspect morphology (pp. 199-220). Amsterdam: Benjamins.

Salaberry, R., \& Shirai, Y. (2002). L2 acquisition of tense-aspect morphology. In R. Salaberry \& Y. Shirai (Eds.), The L2 acquisition of tense-aspect morphology (pp. 1-20). Amsterdam: Benjamins.

Sheu, S. (1997). A cross-sectional study of the acquisition of -te iru by intermediate and advanced Taiwanese learners of Japanese [Tyuu-zyookyuu taiwanzin nihongo gakusyuusya ni yoru teiru no syuutoku ni kansuru oodan kenkyuu]. Journal of Japanese Language Teaching [Nihongo Kyooiku], 104, 20-29.

Shirai, Y. (2002). Invited review article. Acquisition of Japanese as a Second Language, 5, 42-61.

Shirai, Y., \& Andersen, R. W. (1995). The acquisition of tense-aspect morphology. Language, 71, 743-762.

Smith, C. S. (1991). The parameter of aspect. Dordrecht: Kluwer Academic.

Vendler, Z. (1967). Linguistics in Philosophy. Ithaca: Cornell University Press.

Weist, R. M. (2002). The first language acquisition of tense and aspect: A review. In R. Salaberry \& Y. Shirai (Eds.), The L2 acquisition of tense-aspect morphology (pp. 21-78). Amsterdam: Benjamins. 